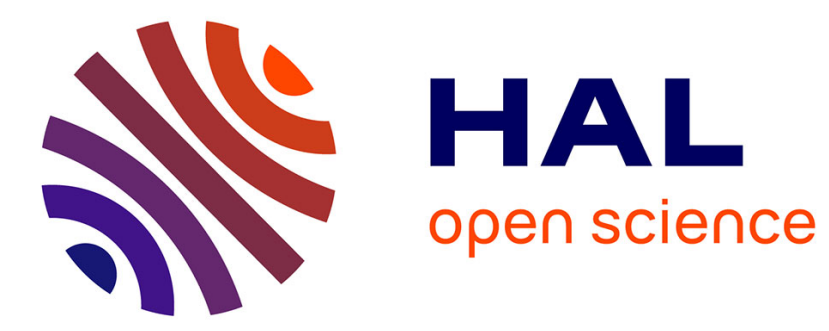

\title{
Intraspecific interference in forage crops. Biological density and its implication in the prediction of association performance
}

\author{
Luisa Zannone
}

\section{- To cite this version:}

Luisa Zannone. Intraspecific interference in forage crops. Biological density and its implication in the prediction of association performance. Agronomie, 1985, 5 (4), pp.287-296. hal-00884761

\section{HAL Id: hal-00884761 https://hal.science/hal-00884761}

Submitted on 1 Jan 1985

HAL is a multi-disciplinary open access archive for the deposit and dissemination of scientific research documents, whether they are published or not. The documents may come from teaching and research institutions in France or abroad, or from public or private research centers.
L'archive ouverte pluridisciplinaire HAL, est destinée au dépôt et à la diffusion de documents scientifiques de niveau recherche, publiés ou non, émanant des établissements d'enseignement et de recherche français ou étrangers, des laboratoires publics ou privés. 


\title{
Intraspecific interference in forage crops. Biolo- gical density and its implication in the predic- tion of association performance
}

\author{
Luisa ZANNONE \\ Istituto Sperimentale per le Colture Foraggere, Lodi, Italy
}

From a series of experiments on intraspecific interference in such forage crops as lucerne, red clover, tall fescue and cocksfoot, some general conclusions have been drawn on the relationship existing between binary association performance and the ratio between the monocultures, as far as vigour expressed by dry matter yield is concerned. Starting from this relationship, a tentative model for the prediction of association performance has been presented, based on the average monoculture performance as well as on the ratio between pairs of monoculture values.

Additional key words : Competition, heterogeneity, homogeneity, yield, vigour.

Interférence intraspécifique en cultures fourragères. La densité biologique et ses implications dans la prédiction des performances des associations.

D'après une série d'expériences sur l'interférence intraspécifique chez quelques plantes fourragères, telles que luzerne, trèfle violet, fétuque élevée et dactyle, on tire quelques conclusions sur le type de relation qui existe entre la performance des associations binaires et le rapport de vigueur entre les deux cultures pures intéressées. A partir de cette relation, on présente un modèle de prévision de la performance des associations, basé sur la valeur moyenne de chaque couple de monocultures aussi bien que sur le rapport de vigueur entre ces deux mêmes cultures pures.

Mots clés additionnels : Compétition, hétérogénéité, homogénéité, production, vigueur.

\section{INTRODUCTION}

From a series of experiments on intraspecific interference in such forage crops as lucerne (Medicago sativa L.) (ROTILI, 1975, 1979 ; ROTILI \& ZANNONE, 1970, 1971, 1975 ; ROTILI et al., 1976 ; ASSEMAT, 1977), red clover (Trifolium pratense L.) (ROTILI et al., 1977b; JACQUARD et al., 1978), cocksfoot (Dactylis glomerata L.) (ROTILI \& ZANNONE, 1977) and tall fescue (Festuca arundinacea Schreb.) (ROTILI et al., 1977a), some general aspects of interference phenomena, common to all the said species, have recently been discussed (ZANNONE et al., 1983).

The principal aspect is that, in all these species, interference between plants of different "genotypes" leads to plastic responses (JACQUARD, 1972), characterized by situations of competition. These situations have been described and discussed chiefly for binary associations, but genotype performance in more complex associations has been proved to follow the same rules.

The performance of genotypes in association has been explained by ROTILI (ROTILI \& ZANNONE, 1970 ; JACQUARD, 1972 ; ROTILI, 1979) with the hypothesis of biological density : at any given numerical density and with whatever unit of measurement (individual plant or plot), a genotype in a mixture shows a better performance than in monoculture when it finds, because of the presence of a weaker partner, a lower biological density than in pure stand; on the in contrast, if it finds a greater biological density (because of the presence of a stronger partner) it will give a lower yield than in monoculture.

The parameter of biological density was defined by 
RoTILI (1979) as the ratio between the actual biomass (demand of individuals) and the potential biomass (resources available in the environment). For the aerial part, the range of variation of this ratio is from zero to one. The zero value corresponds to the moment just after cutting, when the actual biomass practically does not exist ; the value 1 is reached when the actual biomass exploits all the available resources of the environment. For an individual plant, as well as for a population of plants, the optimal growing conditions correspond to biological density values under 1.

After the cuttings, the individuals which grow more rapidly have an advantage over their neighbours, chiefly because of the greater amount of light they can shut out. This advantage increases with time, and consequently the population becomes more and more heterogeneous, the vigorous individuals increasing in vigour while the weaker ones decrease. The mortality of the weaker plants is a function of the genetic heterogeneity of the population, plant death being the result of delay in growth accumulated in time.

Each genotype has an optimal biological density : its realization depends upon many factors, among which the partner in the mixture is determinant. At the individual plant level, biological density has been proved to display its effects like numerical density : the variation in yield according to the variation in numerical density depends indeed, in monoculture, upon the vigour of the genotype (ZANNONE et al., 1983). In a binary mixture, this effect is enhanced by the presence of the partner : at any given density, the vigorous genotypes perform in mixture as if at a lower density, while the weak genotypes perform as if at a higher density (ROTILI \& ZANNONE, 1971). Such a trend varies in intensity but not in direction through the cuttings : biological density and cutting effects may interfere.

The purpose of this note is : 1) to define how biological density manifests itself at the association level (that is at the level of the mixed populations), and
2) to discuss the implication of biological density in the prediction of association performance, based on monoculture performance.

\section{MATERIALS, METHODS AND RESULTS}

The experiments on intraspecific interference are summarized in table 1. As they are all published, we refer to the literature references. All these experiments were planned as diallel association schemes in order to allow analysis of the experimental data according to the Gallais model (GALlaIS, 1970). The results of such analysis always revealed, for every species and all the characteristics analysed, a constant predominance of the General Dominating Ability (G.D.A.) on the General Association Ability (G.A.A.) as table 2 shows. This is a consequence of the general plastic responses of the constituents of the mixtures in situations of competition.

The plastic responses were expressed by the formula :

$$
\frac{\mathrm{n} \cdot \mathrm{Y}_{\mathrm{i} / \mathrm{j}}}{\mathrm{Y}_{\mathrm{ii}}}-1
$$

In this formula the term $\frac{n . Y_{i / j}}{Y_{i i}}$ corresponds to the " relative yield » of DE WIT \& VAN DEN BERGH (1965) multiplied by a factor $n$ which relates the genotype in mixture to the same unit area of the genotype in monoculture.

This formula allowed us to analyse the plastic responses of the genotypes in mixture by the same procedure whatever the proportion of each genotype in the association. By plotting in a graph the data of several subsequent cuttings, the trend of the variation in time of the situations within the mixtures was visualized.

Critical analysis of the different possible models (DE WIT \& VAN DEN BERGH, 1965 ; CHALBI, 1967 ;

TABLE 1

Intraspecific interference in forage crops : description of the experiments. Interférence intraspécifique chez les plantes fourragères. Description des expériences.

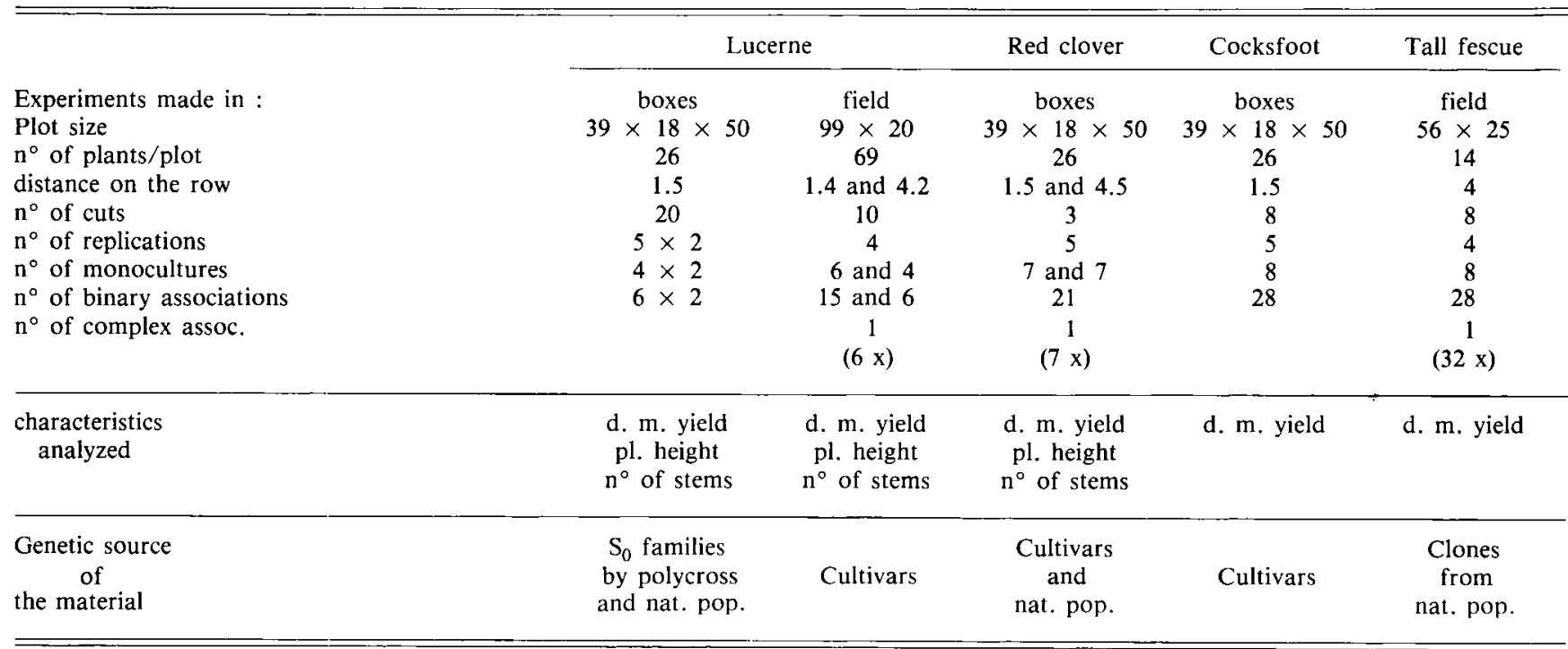


TABLE 2

Relative importance of the GDA vs GAA $\left(s_{G D A}^{2} / s_{G A A}^{2}\right)$ through successive cuttings. Importance relative de l'A.G.D. par rapport à l'A.G.A. au cours des coupes $\left(s_{A . G . D .}^{2} / s_{\text {A.G.A }}^{2}\right)$.

\begin{tabular}{|c|c|c|c|c|c|c|c|c|c|c|c|}
\hline & Cuts & 1 & 2 & 3 & 4 & 5 & 6 & 7 & 8 & 9 & 10 \\
\hline \multicolumn{12}{|l|}{ Lucerne } \\
\hline $\begin{array}{l}\text { Dry matter yield } \\
\text { Plant height } \\
n^{\circ} \text { of stems/plant }\end{array}$ & & $\begin{array}{l}3.8 \\
2.2 \\
1.6\end{array}$ & $\begin{array}{l}7.0 \\
3.7 \\
2.8\end{array}$ & $\begin{array}{l}4.8 \\
2.5 \\
7.2\end{array}$ & $\begin{array}{r}3.6 \\
2.4 \\
13.0\end{array}$ & 6.3 & 9.2 & & & $\begin{array}{r}11.8 \\
4.7 \\
3.6\end{array}$ & 12.2 \\
\hline \multicolumn{12}{|l|}{ Red clover } \\
\hline $\begin{array}{l}\text { Dry matter yield } \\
\text { Plant height } \\
\mathrm{n}^{\circ} \text { of stems/plant }\end{array}$ & & $\begin{array}{l}4.2 \\
0.9 \\
1.3\end{array}$ & $\begin{array}{r}10.1 \\
2.1 \\
13.9\end{array}$ & $\begin{array}{r}12.1 \\
3.9 \\
7.0\end{array}$ & & & & & & & \\
\hline \multicolumn{12}{|l|}{ Tall fescue } \\
\hline Dry matter yield & & 1.8 & 2.6 & 3.1 & 1.9 & 1.6 & 1.5 & 2.0 & 3.3 & & \\
\hline \multicolumn{12}{|l|}{ Cocksfoot } \\
\hline Dry matter yield & & 14.7 & 45.4 & 4.8 & 3.2 & 7.0 & 11.0 & 23.9 & 34.4 & & \\
\hline
\end{tabular}

VAN NGUYEN, 1969 ; Gallais, 1970) is beyond the scope of this paper ; an exhaustive critical review was made by SPITTERS (1979). We only stress that all the results of our experiments fitted well with a proportional model, and that the plastic responses always revealed situations of competition.

In general, these situations were represented by two divergent lines indicating an increasing effect of competition through the cuttings; in some cases the two lines fluctuated alternately over and under the horizontal line (representing the monoculture value). Such fluctuation indicated either a situation of neutralism (the fluctuation being small and at random) or an actual fluctuation of the plastic response of the two partners. All these three different features were found in cocksfoot : the actual fluctuations were proved to correspond to a difference between the partners not only in vigour but in earliness of development and earing time as well.

In our experiments, when the advantage of one partner was compensated by the disadvantage of the other, the association performance never overtook the better monoculture performance ; but when there was an over-compensation in favour of one partner, the association performance should overtake the better monoculture. This was the case of some binary associations in cocksfoot, where the gain nevertheless did not overpass the $5 \%$ statistical level of significance. Similar results, always in cocksfoot, have been presented by GALLAIS (1973).

\section{DISCUSSION}

The greatest part of our intraspecific results concerns lucerne ; therefore, the discussion is chiefly focused on this species; the agreement or disagreement with the results on other species will be discussed afterwards.

\section{A. Lucerne}

\section{Biological density at the level of mixed populations}

ROTILI (1979) showed the relationship existing between the homogeneity of a lucerne canopy and its yield capacity, as a result of physiological homogeneity for resistance to cutting stress.

We wanted to know in which way such a relationship was manifested within the binary associations. For this purpose we analyzed the relationship either between the homogeneity within the binary association and the homogeneity between the monocultures, or the relationship between both these types of homogeneity and the yield performance of the association.

a) Relationship between homogeneity within mixtures and homogeneity between monocultures

At first, we investigated how the homogeneity or heterogeneity for vigour between pairs of monocultures was reflected in binary mixtures.

As an index of the between-monocultures homogeneity for vigour we took the ratio between the two pure stand performances $\left(Y_{\mathrm{ii}} / \mathrm{Y}_{\mathrm{jj}}\right)$, while the ratio between the two partners' performances $\left(Y_{i / j} / Y_{j / i}\right)$ was taken as an index of the phenotypic homogeneity for vigour within the mixture.

The maximum degree of homogeneity was represented by :

$$
\mathrm{Y}_{\mathrm{ii}} / \mathrm{Y}_{\mathrm{jj}}=1 \text { and } \mathrm{Y}_{\mathrm{i} / \mathrm{j}} / \mathrm{Y}_{\mathrm{j} / \mathrm{i}}=1 \text {. }
$$

In table 3 the coefficients of correlation between these two parameters are given for dry matter yield, plant height and stem number per plant. According to the diallel association scheme, every set of binary mixtures is referred to one recurrent component.

Not only the vigour (expressed by the dry matter yield per plot), but also the characteristics more responsible for its formation (plant height and stem 
TABLE 3

Correlation coefficients for the ratio between the partners in the association $\left(Y_{i / j} / Y_{j / j}\right)$ vs the ratio between the monocultures $\left(Y_{i j} / Y_{j j}\right)$ in lucerne. Degrees of freedom : 3.

Coefficients de corrélation du rapport des partenaires de chaque association $\left(Y_{i / j} / Y_{j / i}\right)$ avec le rapport des deux cultures pures correspondantes $\left(Y_{i i} / Y_{j j}\right)$ chez la luzerne. Degrés de liberté : 3.

\begin{tabular}{cccc}
\hline $\begin{array}{c}\text { Recurrent } \\
\text { genotype }\end{array}$ & $\begin{array}{c}\text { Dry matter yield/ } \\
\text { experimental unit }\end{array}$ & Plant height & $\begin{array}{c}\text { Stem number/ } \\
\text { plant }\end{array}$ \\
\hline A & $0.97^{* * *}$ & $0.99^{* * *}$ & $0.99^{* * *}$ \\
B & $0.98^{* * *}$ & $0.99^{* * *}$ & $0.96^{* * *}$ \\
C & $0.97^{* * *}$ & $0.99^{* * *}$ & $0.96^{* * *}$ \\
D & $0.97^{* * *}$ & $0.97^{* * *}$ & $0.98^{* * *}$ \\
E & $0.90^{* *}$ & $0.98^{* * *}$ & $0.96^{* * *}$ \\
F & $0.94^{* *}$ & $0.99^{* * *}$ & $0.96^{* * *}$ \\
\hline
\end{tabular}

number) showed very highly significant coefficients : the more similar the monocultures, the more homogeneous were the mixtures. But the coefficients of correlation were not sufficient to illustrate the relationship : in fact, the scatter diagrams for dry matter yield data (fig. 1) showed that the spots did not
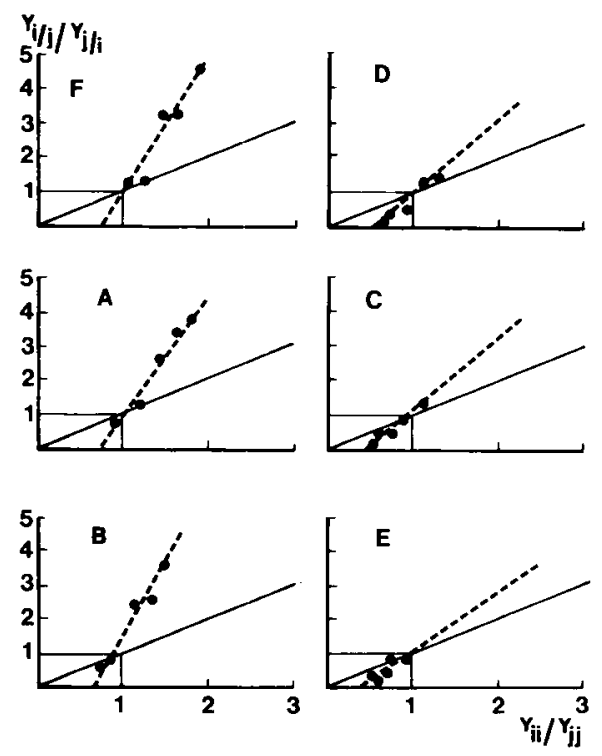

Figure 1

Linear regression of the ratio between the two partners of each association on the ratio between the two corresponding monocultures, in lucerne.

In ordinate the ratio between the two partners : $Y_{i / j} / Y_{j / i}$ In abscissa the ratio between the monocultures : $Y_{i i} / Y_{j j}$.

Régression linéaire du rapport des 2 partenaires de chaque association sur le rapport des 2 cultures pures correspondantes chez la luzerne.

En ordonnée : rapport des partenaires.

En abscisse : rapport des cultures pures.

follow the bisector, but deviated from it more or less, according to the recurrent genotype. Considering at first the genotypes F, A, B (the more vigorous ones) we noted that the spots started near the point of coordinates $(1,1)$ and then were scattered towards the upper part of the diagram, with a slope much over unity ; this meant that when two genotypes showed the same vigour in monoculture they still remained at equilibrium in mixture. However, when they were different in pure stand, their difference rapidly increased in mixture to the advantage of the better partner. Such a performance was due to biological density : when two genotypes were similar in vigour in monoculture, their biological density did not change in mixture ; when they were different in monoculture, the biological density they found in mixture was lighter for the vigorous partner and heavier for the weaker one ; consequently, their difference (expressed by the ratio between them) increased.

The same was true for the genotypes $\mathrm{D}$ (medium) and $\mathrm{C}, \mathrm{E}$ (weak) : these two last generally found in mixture a greater biological density than in monoculture ; as a consequence, the spots were scattered in the lower part of the diagram, under the bisector.

We then analysed the consequence of this variation in biological density on the yield capacity of the associations. For that, we considered the relationship between the yield performance of each association $Y_{i j}$ and either the ratio between the partners in mixture $\left(\mathrm{Y}_{\mathrm{i} / \mathrm{j}} / \mathrm{Y}_{\mathrm{j} / \mathrm{i}}\right)$ or the ratio between the two monocultures $\left(\mathrm{Y}_{\mathrm{ii}} / \mathrm{Y}_{\mathrm{jj}}\right)$.

b) Relationship between the association yield performance $\left(Y_{i j}\right)$ and the ratio between the two partners $\left(Y_{i / j} / Y_{j / i}\right)$

When a recurrent partner is considered at the numerator, the association yield performance results is negatively correlated with the ratio between the two partners. In figure 2 the association yield data have been plotted, for every set of mixtures, against the ratio between every two partners. As a general remark, we stress that, when the absolute value of the ratio between the two partners increased, the association yield decreased.

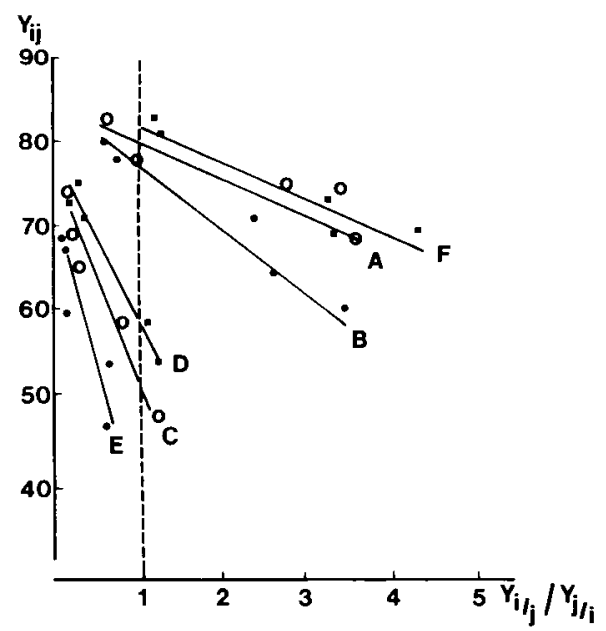

Figure 2

Linear regression of dry matter yield of binary associations on the ratio between the two partners, in lucerne.

In ordinate the association dry matter yield per plot : $Y_{i j}$ In abscissa the ratio between the two partners : $Y_{i / j} / Y_{j / i}$.

Régression linéaire du rendement des associations binaires sur le rapport des 2 partenaires chez la luzerne.

En ordonnée : rendement des associations (g M.S./parcelle).

En abscisse : rapport des 2 partenaires. 
The scatter diagram appeared to be divided into two parts. On one side there were the points referred to the more vigorous genotypes $\mathrm{F}, \mathrm{A}, \mathrm{B}$, on the other side, the points referred to the weaker ones D, C, E.

In the first group, the better performing mixtures showed a ratio between the partners near unity. As the difference between the partners in the mixture increased, the yield performance decreased. Here we find confirmed the statement of ROTILI (1979) about the positive relation between homogeneity and yield performance of a lucerne canopy.

In the second group, we observed that the mixtures in which the ratio between the partners is near unity yielded less that the more heterogeneous mixtures. This was only an apparently contradictory result because, in fact, the more performing mixtures were those in which the participation of the recurrent weaker partner to the biomass production was very low : these mixtures have indeed to be considered as pure stands of the vigorous partner. In this group, the mixtures in which the partners were equally weak gave, despite this similarity, only a poor performance. The similarity was therefore necessary but not sufficient to give a good performance : what was necessary was high vigour and high homogeneity either within or between the partners. Every time a partner in the mixture was replaced by a more vigorous one, the yield performance of the mixture increased. The best associations were indeed those whose partners yielded most.

The ratio between the two partners of each association is considered as an index of the variation in the biological density : its value increased when the biological density of the recurrent genotype (at the numerator) decreased. As a consequence, the yield per plant of the recurrent genotype increased, while the yield of the mixture decreased.

c) Relationship between association yield performance $\left(Y_{i j}\right)$ and the ratio between the two monocultures $\left(Y_{i i} / Y_{j j}\right)$

When a recurrent partner was considered at the numerator, the association yield performance results correlated negatively with the ratio between the two monocultures. This is shown in figure 3 , in which the association dry matter data have been plotted against the ratio between the monocultures, according to the same criterion as figure 2 . The same considerations are valid here. The only difference between the two schemes was in the divergency of the regression lines: the larger divergency observed in figure 2 was a consequence of the variation in biological density, occurring within the mixtures but of course not between the monocultures.

In table 4 are shown the correlation coefficients for the association performance versus the ratio between the monocultures, not only for dry matter yield data but for plant height and stem number as well. Here again, we observed that the correlation coefficients were very highly significant for all the three characteristics. In particular, the strict correlation existing between the dry matter yield of the associations and the ratio between pairs of monocultures was interesting from the point of view of the prediction of association performance.

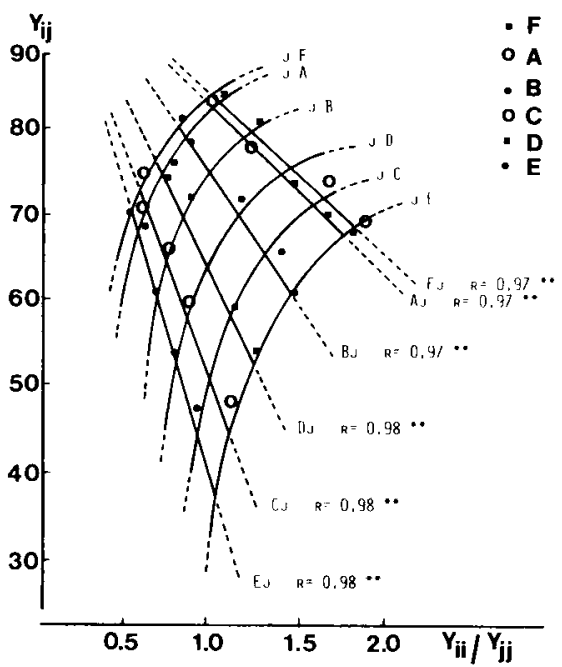

Figure 3

Linear regression of dry matter yield of binary associations on the ratio between the two corresponding monocultures, in lucerne. In ordinate the association dry matter yield per plot : $Y_{i j}$. In abscissa the ratio between the two corresponding monocultures : $Y_{i i} / Y_{j j}$.

Régression linéaire du rendement des associations binaires sur le rapport des 2 cultures pures correspondantes chez la luzerne. En ordonnée : performance des associations (g M.S./parcelle). En abscisse : rapport des 2 cultures pures.

TABLE 4

Coefficients of correlation for the binary association performance $\left(Y_{i j}\right)$ versus the ratio between the two monocultures $\left(Y_{i i} / Y_{j j}\right)$ in lucerne. Degrees of freedom : 3.

Coefficients de corrélation de la performance des associations binaires $\left(Y_{i j}\right)$ avec le rapport des deux cultures pures correspondantes $\left(Y_{i i} / Y_{j j}\right)$ chez la luzerne. Degrés de liberté : 3.

\begin{tabular}{cccc}
\hline \hline $\begin{array}{c}\text { Recurrent } \\
\text { genotype }\end{array}$ & $\begin{array}{c}\text { Dry matter yield/ } \\
\text { experimental unit }\end{array}$ & Plant height & $\begin{array}{c}\text { Stem number/ } \\
\text { plant }\end{array}$ \\
\hline A & $-0.97^{* *}$ & $-0.99^{* *}$ & $-0.97^{* *}$ \\
B & $-0.99^{* *}$ & $-0.99^{* *}$ & $-0.99^{* *}$ \\
C & $-0.97^{* *}$ & $-0.96^{* *}$ & $-0.98^{* *}$ \\
D & $-0.98^{* *}$ & $-0.96^{* *}$ & $-0.95^{* *}$ \\
E & $-0.99^{* *}$ & $-0.90^{* *}$ & $-0.95^{* *}$ \\
F & $-0.97^{* *}$ & $-0.98^{* *}$ & $-0.84 \mathrm{~ns}$ \\
\hline
\end{tabular}

\section{Prediction of mixture performance from mono- culture performance}

The ranking of the binary associations generally followed the ranking of the monocultures, in the sense that the more performing associations were those constituted by the best monocultures and the poorest associations derived from the poorest monocultures. It seemed possible consequently to estimate binary association performance from the two monocultures performances.

For the fifty-fifty associations the estimation was based on the expression :

$$
\mathrm{y}_{i j}^{\prime}=\frac{\mathrm{Y}_{\mathrm{ii}}+\mathrm{Y}_{\mathrm{jj}}}{2}
$$


and the estimated points lay on the bisector of the diagram of co-ordinates

$$
y=Y_{i j}^{\prime} \quad \text { and } \quad x=\frac{Y_{i i}+Y_{j j}}{2}
$$

The simplest way to estimate the performance of a set of binary associations seems to be the calculation of the average of every pair of monocultures for the whole set of associations. In figure 4 the actual values $\mathrm{Y}_{\mathrm{ij}}$ of the possible 15 binary associations between the 5 genotypes A, B, D, E, F, are plotted against the theoretical values $\left(\mathrm{Y}_{\mathrm{ii}}+\mathrm{Y}_{\mathrm{jj}}\right) / 2$. The bisector should represent the prediction line, but the experimental data do not follow it : a marked deviation is evident for the lowest as well as for the highest values.

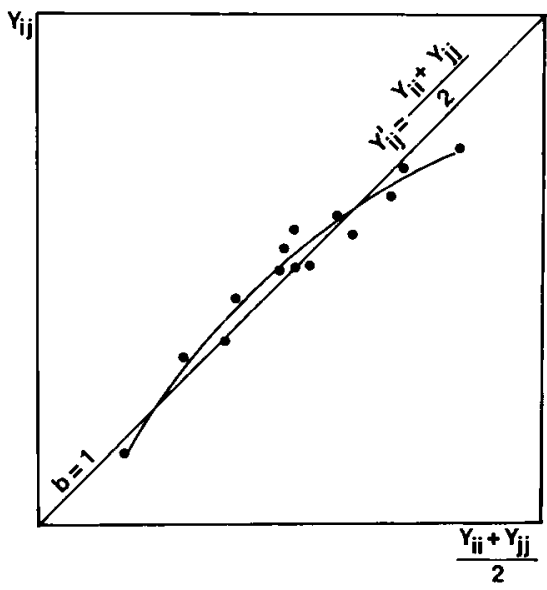

Figure 4

Scatter diagram for dry matter yield of binary associations versus the average dry matter yield of corresponding pairs of monocultures, in lucerne.

In ordinate the binary association dry matter yield $Y_{i j}$ in $g / p l o t$. Inabscissa the average dry matter yield of pairs of monocultures $\left(Y_{i i}+Y_{j j}\right) / 2$, in $\mathrm{g} /$ plot.

Luzerne. Diagramme de dispersion du rendement des associations binaires selon le rendement moyen de chaque couple de cultures pures.

En ordonnée : rendement des associations binaires $(g$ M.S./parcelle).

En abscisse : rendement moyen de chaque couple de cultures pures (g M.S./parcelle).

From figure 5 we can see that this deviation was chiefly due to the genotypes $\mathrm{F}$ (most vigorous) and $\mathrm{E}$ (weakest) ; A and C deviated moderately, while B and $\mathrm{D}$ followed fairly well the prediction line. The slope of the regression line was inferior to the bisector in the vigorous genotypes, while the weak genotype showed a regression line slope greater than the bisector.

The problem was therefore to adjust the slope of the prediction line towards the actual, unknown, line. For that, we had to fix three points :

a) the appropriate coefficient of regression for the slope correction

We used the ratio between the monocultures, considering the expression;

$$
Y_{i i} / Y_{j j}=a+b \cdot \frac{Y_{i i}+Y_{j j}}{2}
$$
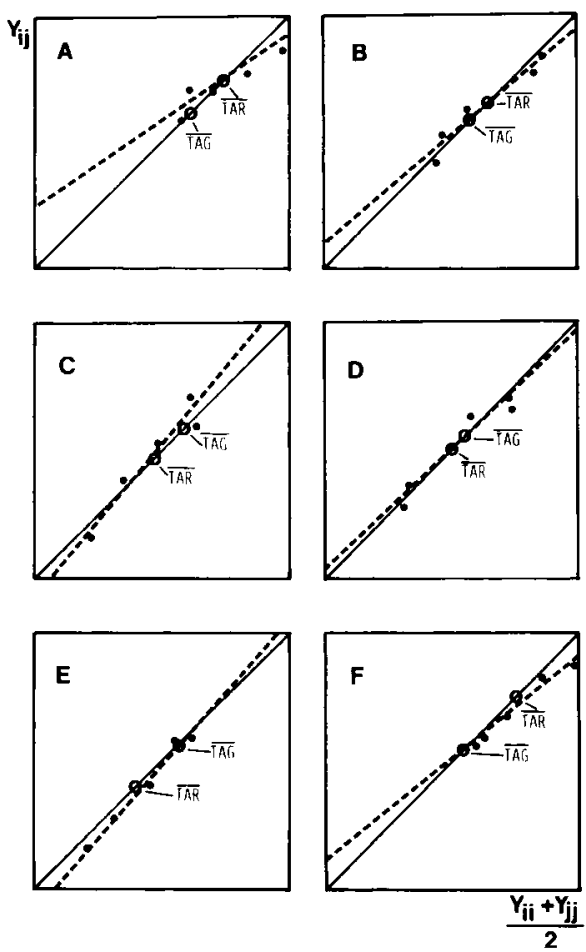

Figure 5

Scatter diagram for dry matter yield of binary associations versus the average dry matter yield of corresponding pairs of monocultures in lucerne. The different sets of associations, referred to each recurrent genotype, are separately considered.

In ordinate the dry matter yield in $g /$ plot of the associations $Y_{i j}$. In abscissa the average dry matter yield of pairs of monocultures $\frac{Y_{\mathrm{ii}}+\mathrm{Y}_{\mathrm{jj}}}{2}$.

The dotted lines are the experimental regression lines; the bisectors represent the estimated regression lines. $\overline{T A R}$ : average of every set of 5 associations; $\overline{T A G}$ : average of the whole set of 15 associa tions.

Luzerne. Diagramme de dispersion du rendement des associations binaires selon le rendement moyen de chaque couple de cultures pures. Les divers groupes d'associations sont considérés séparément selon le génotype récurrent.

En ordonnée : rendement des associations ( $g$ M.S./parcelle).

En abscisse : rendement moyen de chaque couple de cultures pures.

Les lignes en pointillés représentent les droites expérimentales. Les bissectrices représentent les droites estimées.

$\overline{T A R}$ : moyenne théorique de chaque groupe de 5 associations.

$\overline{T A G}:$ moyenne générale des 15 associations possibles.

b) The barycentric point for the rotation of the regression line

For that it was possible to choose either the average theoretical value of each recurrent genotype (T.A.R.) or the general average value of the whole set of 15 theoretical associations (T.A.G.).

\section{c) The direction of line rotation}

As figure 5 shows, the more vigorous genotypes caused a decrease in slope of the prediction line while the weakest ones caused an increase in slope ; in other words, the more vigorous genotypes caused a correction $(+.-)$ around the barycentric point, while the weaker ones caused a correction $(-,+)$.

In the absence of experimental mixtures, the choice between the T.A.R. and the T.A.G. barycentric points presented some difficulties. In our tentative approach 
we tried both these barycentric points (see Appendix). In table 5 the results of both these corrections are presented in terms of coefficient of regression : in some cases the estimated coefficient of regression « $b$ » was closer to the experimental « $b$ » if estimated around the point T.A.R. ; in other cases the opposite was true ; in the absence of experimental mixtures, the application of both these corrections could represent a confidence interval around the prediction line.

\section{TABLE 5}

Lucerne. Comparison between the experimental linear regression coefficients and prediction line coefficients. Luzerne. Comparaison entre les coefficients de régression linéaire expérimentaux et ceux de la droite de prévision.

\begin{tabular}{cccc}
\hline \hline Recurrent genotype & $\mathrm{b}$ & $\mathrm{b}^{\prime}$ & $\mathrm{b}^{\prime \prime}$ \\
\hline F & 0.77 & 0.61 & 0.96 \\
A & 0.59 & 0.67 & 0.79 \\
B & 0.81 & 0.77 & 0.85 \\
D & & & \\
C & 0.94 & 0.82 & 0.82 \\
E & 1.13 & 1.16 & 1.15 \\
& 1.11 & 1.14 & 1.08 \\
\hline
\end{tabular}

$\mathrm{b}=$ experimental regression line

$\mathrm{b}^{\prime}=$ estimation around the point $\overline{\mathrm{TAR}}$ (theoretical average value of every set referred to each recurrent genotype)

$b^{\prime \prime}=$ estimation around the point $\overline{\mathrm{TAG}}$ (general average value of the whole set of 15 theoretical associations)

\section{B. Red clover}

In this species, the ratio between the partners of the binary associations still appeared to be positively correlated with the ratio between the monocultures; the correlation between the association yield performance and the two said parameters seemed to depend upon the recurrent genotype ; in particular, correlation was absent in genotype D (see table 6).

\section{TABLE 6}

Red clover. Coefficients of correlation for : (a) ratio between partners versus ratio between monocultures (b) association performance versus ratio between partners (c) association performance versus ratio between monocultures Degrees of freedom : 4.

Trèfle violet. Coefficients de corrélation:

a) du rapport des 2 partenaires avec le rapport des 2 cultures pures b) de la performance des associations avec le rapport des partenaires

c) de la performance des associations avec le rapport des cultures pures.

Degrés de liberté : 4.

Recurrent genotype

(a)

Correlation coefficients for

\begin{tabular}{lll}
\multicolumn{1}{c}{$(\mathrm{a})$} & \multicolumn{1}{c}{ (b) } & (c) \\
$0.97^{* * *}$ & $-0.93^{* *}$ & $-0.99^{* *}$ \\
$0.98^{* * *}$ & -0.69 & -0.70 \\
$0.95^{* * *}$ & $-0.80^{*}$ & -0.76 \\
$0.98^{* * *}$ & -0.07 & -0.00 \\
$0.85^{*}$ & -0.60 & -0.75 \\
$0.97^{* * *}$ & $-0.89^{* *}$ & $-0.85^{*}$ \\
$0.99^{* * *}$ & $-0.85^{* *}$ & $-0.98^{*}$
\end{tabular}

This lack of significance seemed to be due to association $\mathrm{D}+\mathrm{C}$, the yield of which was greater than expectation ; by comparing the dry matter yield data with those of plant height and stem number we realized that such an over-production could be due to a stem number greater than the expectation. The association $D+G$ indeed showed a stem number per plant above expectation as well, but in this last case no effect was observed on dry matter yield, probably because of thinner stems. By considering the complex relationship existing between the different component of vigour, we observed that genotype $\mathrm{D}$ had to be considered as an outsider, and that the other genotypes analyzed in our experiment had to be partitioned into two different groups : A, B, G and C, E, F. This should explain the lack of statistical significance of some correlation coefficients.

\section{Tall fescue}

In this species, the ratio between the partners of the associations was always strictly correlated with the ratio between the monocultures for dry matter yield (table 7).

As concerns the correlation between the association yield performance and the ratio between the partners for vigour, the statistical significance was variable according to the considered genotypes. In particular, it was very low for genotype 3. This last was indeed characterized by a constant earing after each cutting : its yield performance in monoculture appeared therefore much higher when compared with the other genotypes ; in mixture, its domination effect on the partners generated a kind of plateau in dry matter production, as the value of the regression line coefficient shows :

$\mathrm{Y}_{1}=69.8-28.94 \mathrm{x}$
$\mathrm{Y}_{2}=66.5-41.12 \mathrm{x}$
$\mathrm{Y}_{3}=62.6-4.91 \mathrm{x}$
$\mathrm{Y}_{4}=67.3-30.50 \mathrm{x}$
$\mathrm{Y}_{5}=66.2-19.92 \mathrm{x}$
$\mathrm{Y}_{6}=66.7-25.04 \mathrm{x}$
$\mathrm{Y}_{7}=68.4-20.78 \mathrm{x}$
$\mathrm{Y}_{8}=59.3-21.39 \mathrm{x}$

Concerning prediction of the association performance based on monoculture performance, we observed in this species a good agreement between the experimental and the theoretical data (fig. 6). The experimental points followed the prediction line pretty well. Correction therefore seemed unnecessary ; in fact, it did not bring any advantage (table 8 ). The correlation between experimental and theoretical data increased with successive cuttings, as a consequence of the increasing difference between the genotypes : the prediction made at the end of the first year ( 6 cuts) or after 8 cuts seemed to be sufficiently correct.

\section{Cocksfoot}

For this species, the statistical significance of the three correlations till now discussed appeared to 
TABLE 7

Tall fescue. Coefficients of correlation for :

(a) ratio between partners versus ratio between monocultures

(b) association performance versus ratio between partners

(c) association performance versus ratio between monocultures

Degree of freedom : 5.

Fétuque élevée. Coefficients de corrélation :

a) du rapport des 2 partenaires avec le rapport des 2 cultures pures

b) de la performance des associations avec le rapport des partenaires

c) de la performance des associations avec le rapport des cultures pures.

Degrés de liherté : 5.

\begin{tabular}{clll}
\hline \hline & \multicolumn{3}{c}{ Correlation coefficients for } \\
Recurrent genotype & \multicolumn{1}{c}{ (b) } & (c) \\
\hline 1 & $0.95^{* * *}$ & $-0.97^{* *}$ & $-0.92^{* *}$ \\
2 & $0.77^{*}$ & $-0.78^{*}$ & $-0.97^{* *}$ \\
3 & $0.90^{* * *}$ & -0.43 & $-0.56^{*}$ \\
4 & $0.90^{* * *}$ & $-0.74^{*}$ & $-0.87^{* *}$ \\
5 & $0.93^{* * *}$ & -0.68 & $-0.89^{* *}$ \\
6 & $0.95^{* * *}$ & $-0.85^{* *}$ & $-0.94^{* *}$ \\
7 & $0.88^{* * *}$ & $-0.77^{*}$ & $-0.95^{* *}$ \\
8 & $0.94^{* * *}$ & $-0.84^{* *}$ & $-0.90^{* *}$ \\
\hline
\end{tabular}
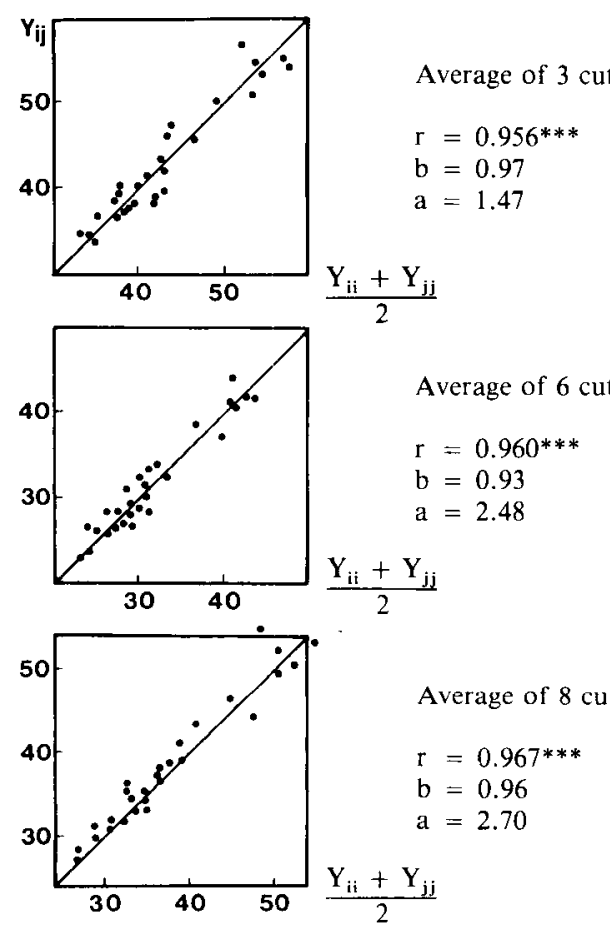

Figure 6

Scatter diagram for dry matter yield of binary associations versus the average dry matter yield of corresponding pairs of monocultures in tall fescue.

In ordinate the binary association dry matter yield $Y_{i j}$ in $\mathrm{g} / \mathrm{plot}$. In abscissa the average dry matter yield of pairs of monocultures $\frac{\mathrm{Y}_{\mathrm{ii}}+\mathrm{Y}_{\mathrm{jj}}}{2}$ in $g /$ plot.

Fétuque élevée. Diagramme de dispersion du rendement des associations selon le rendement moyen de chaque couple de cultures pures. En ordonnée : rendement des associations binaires (g M.S./parcelle).

En abscisse : rendement moyen de chaque couple de cultures pures.

depend upon the recurrent genotypes (table 9). It has to be stressed that the range of variation between the monocultures was in this experiment very narrow :
TABLE 8

Tall fescue. Comparison between the experimental linear regression coefficients and prediction line coefficients. Fétuque élevée. Comparaison entre les coefficients de régression linéaire expérimentaux et ceux de la droite de prévision.

\begin{tabular}{cccc}
\hline \hline Recurrent genotype & $b$ & $b^{\prime}$ & $b^{\prime \prime}$ \\
\hline 1 & 1.10 & 1.21 & 1.20 \\
2 & 1.02 & 1.14 & 1.12 \\
3 & 0.43 & -0.47 & 0.91 \\
4 & 1.18 & 1.19 & 1.16 \\
5 & 0.91 & 0.74 & 0.74 \\
6 & 0.99 & 1.22 & 1.21 \\
7 & 0.90 & 0.74 & 0.78 \\
8 & 0.85 & 1.21 & 1.17 \\
\hline
\end{tabular}

$\mathrm{b}=$ experimental regression line

$\mathrm{b}^{\prime}=$ estimation around the point $\overline{\mathrm{TAR}}$ (theoretical average value of every set referred to each recurrent genotype)

$\mathrm{b}^{\prime \prime}=$ estimation around the point $\overline{\mathrm{TAG}}$ (general average value of the whole set of 15 theoretical associations).

this may be one of the causes of non-significance of the correlation coefficients.

Concerning the prediction of association performance based on monoculture performance, we found in this species, as in lucerne, that despite the statistical significance of the correlation coefficients, the prediction could be wrong. In the scatter diagram of figure 7 , we observed that the slope of the regression line was not very different from unity (bisector) but all the experimental points were distributed above the bisector : in this case, therefore, the correction would concern not only the coefficient of linear regression «b », but the coefficient $« a$ » as well.

We found a similar situation in an interspecific association experiment in which the binary associations lucerne + cocksfoot and lucerne + tall fescue were analyzed. Aspects concerning the prediction of association performance in such case will be discussed in a subsequent paper. What is interesting to notice here is that the general type of plastic responses in

\section{TABLE 9}

Cocksfoot. Coefficients of correlation for :

(a) ratio between partners versus ratio between monocultures (b) association performance versus ratio between partners (c) association performance versus ratio between monocultures Degrees of freedom : 5.

Dactyle. Coefficients de corrélation :

a) du rapport des 2 partenaires avec le rapport des 2 cultures pures b) de la performance des associations avec le rapport des partenaires

c) de la performance des associations avec le rapport des cultures pures.

Degrés de liberté : 5.

Recurrent genotype Correiation coefficients for (a) (b) (c)

\begin{tabular}{llll}
\hline 1 & 0.59 & -0.40 & $-0.89^{* *}$ \\
2 & $0.75^{*}$ & $-0.82^{*}$ & -0.72 \\
3 & $0.97^{* *}$ & $-0.83^{*}$ & $-0.92^{* *}$ \\
4 & $0.83^{*}$ & $-0.75^{*}$ & $-0.91^{* *}$ \\
5 & $0.93^{* *}$ & $-0.84^{* *}$ & -0.61 \\
6 & $0.77^{*}$ & -0.27 & -0.72 \\
7 & $0.89^{* * *}$ & $-0.94^{* *}$ & $-0.95^{* *}$ \\
8 & $0.83^{*}$ & -0.58 & -0.59 \\
\hline
\end{tabular}




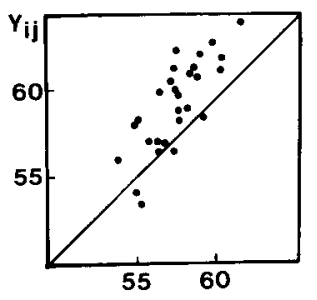

$$
\begin{aligned}
\text { Average of } 3 \text { cuts } \\
r=0.772^{* * *} \\
b=1.18 \\
\mathrm{a}=-8.75 \\
\frac{\mathrm{Y}_{\mathrm{ii}}+\mathrm{Y}_{\mathrm{jj}}}{2}
\end{aligned}
$$

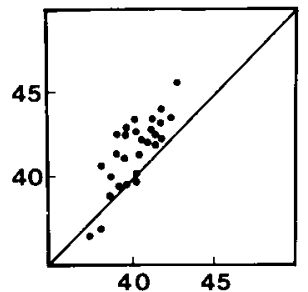

Average of 5 cuts

$r=0.826^{* * *}$

$\mathrm{b}=1.33$

$a=-11.94$

$\frac{Y_{i i}+Y_{j j}}{2}$

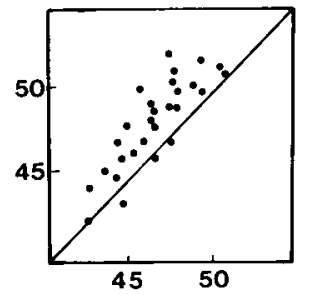

Average of 8 cuts

$r=0.829^{* * *}$

$\mathrm{b}=1.06$

$\mathrm{a}=-6.04$

$\frac{Y_{i i}+Y_{j j}}{2}$

Figure 7

Scatter diagram for dry matter yield of binary associations versus the average dry matter yield of pairs of monocultures in cocksfoot. In ordinate the binary association dry matter yield $Y_{i j}$ in $\mathrm{g} / \mathrm{plot}$. In abscissa the average dry matter yield of pairs of monocultures $\frac{\mathrm{Y}_{\mathrm{ii}}+\mathrm{Y}_{\mathrm{jj}}}{2}$ in $\mathrm{g} /$ plot

Dactyle. Diagramme de dispersion du rendement des associations selon le rendement moyen de chaque couple de cultures pures.

En ordonnée : rendement des associations binaires $(g \mathrm{M}$.S./parcelle).

En abscisse : rendement moyen de chaque couple de cultures pures.

these interspecific associations were characterized by fluctuating lines and this fluctuation proved to be due to a displacement in time of the maximal production of the two partners. Each species showed, in turn, an advantage characterized by a great over-compensation, the consequence of which was over-yielding of mixtures when compared to the average monoculture production. In the scatter diagram of the association yield data against the averages of pairs of monocultures, all the experimental points were located above the bisector, and such dislocation increased with overcompensation. Consequently, it seems possible to infer that overcompensation was the cause of displacement of experimental points above the bisector. Correct prediction of association performance would therefore in such cases require a measure of overcompensation.

\section{CONCLUSIONS}

1. From the series of intraspecific interference data here discussed, chiefly concerning lucerne, but also red clover, tall fescue and cocksfoot, the biological density effect was manifested at the level of the association performance by a regression line relationship, as shown at individual plant level (ZANNONE $e t$ al., 1983).
When a given set of data allows correct computing of correlation coefficients, a linear regression appears indeed to be the fundamental type of relation existing between the partners and the monocultures. Deviations from this rule were sometimes caused either by an insufficient range of variation between the items, or, else, by the presence in the set of considered genotypes of some type so different as to make the correlation spurious. Genotypes D for red clover and 3 for tall fescue are two examples of such spuriousness.

The regression lines arise whenever a set of associations is considered with reference to a recurrent genotype. The slope of each regression line depends upon the vigour of the recurrent genotype. Such a relation between the $b$ coefficient and vigour was still observed at the individual plant level (ZANNONE et al., 1983).

2. The linearity of relationship between the parameters here considered allows good prediction of association performance based on the performance of pairs of monocultures. Nevertheless, the simple average of the two monocultures seems to be insufficient when the range of variation between the monocultures is large or when the overcompensation effect is important ; in such cases, the prediction may be improved by taking into account, beside the average of pairs of monocultures, also the ratio between them. This correction has to be applied to each set of associations separately.

3. In each set of binary associations, every time a partner is replaced by a more vigorous one, the association yield increases following a linear regression. The best associations are those in which the two partners are equally vigorous. When the considered recurrent genotype is a weak genotype, the best associations are those in which the ratio $Y_{i / j} / Y_{j / i}$ is displaced in favour of the more vigorous partner. These associations have to be considered as monocultures of the vigorous partner, because high mortality and weakness make the yield contribution of the other partner almost non-existent.

Reçu le 28 février 1984 Accepté le 12 novembre 1984.

\section{APPENDIX}

Example of calculation. Exemple de calcul

\begin{tabular}{ccccc}
\hline & $Y=$ & $b_{y / x} \cdot x$ & $Y_{i j}^{\prime}$ & $Y_{i j}$ \\
$Y_{i i}+Y_{j j}$ & $Y_{i i} / Y_{j j}$ & & (estimated) & (experimental) \\
\hline 2 & & &
\end{tabular}

\begin{tabular}{crrrr}
\hline GENOTYPE E : & $\overline{T A R}=61.3$ & $b=1.90$ & \\
68.5 & 0.55 & +1.31 & 69.81 & 68.74 \\
62.0 & 0.68 & +1.18 & 63.18 & 60.55 \\
50.5 & 0.91 & -0.96 & 49.54 & 47.96 \\
55.7 & 0.79 & -1.06 & 54.64 & 54.34 \\
70.0 & 0.54 & +1.33 & 71.33 & 69.31
\end{tabular}

GENOTYPE F: $\overline{T A R}=78.15 \quad b=3.99$

$\begin{array}{lllll}89.5 & 1.03 & -3.57 & 85.93 & 83.38 \\ 83.0 & 1.26 & -3.31 & 79.69 & 80.58 \\ 71.5 & 1.68 & +2.85 & 74.35 & 69.78 \\ 76.7 & 1.46 & +3.06 & 79.76 & 73.79 \\ 70.0 & 1.86 & +2.79 & 72.79 & 69.31\end{array}$




\section{REFERENCES}

Assemat L., 1977. Modèles d'analyse de la concurrence entre populations végétales. Thèse Doct. Spécialités Sci. Biol. mention Ecologie, U.S.T.L. Montpellier, $112 \mathrm{p}$.

Chalbi N., 1967. Biométrie et analyse quantitative de la compétition entre génotypes chez la luzerne. Ann. Amélior. Plantes, 17, 119158.

Gallais A., 1970. Modèle pour l'étude des relations d'associations binaire. Biométr. Praxim., 11, 51-30.

Gallais A., 1973. Competition and breeding for yield in cocksfoot, in Evaluation of Breeding Material in Herbage Crops, Eucarpia, Rep. Fodder Crops Meeting, Dublin, 4-7 Sept. 1972, 201-231.

Jacquard P., 1972. Glossaire de termes et définitions. Sect. Plantes Fourragères, EUCARPIA, CEPE, Montpellier, $36 \mathrm{p}$.

Jacquard P., Rotili P., Zannone L., 1978. Les interactions génotype $\times$ milieu biologique : analyse diallèle des aptitudes à l'association entre populations de trèfle violet. Ann. Amélior. Plantes, 28 (3), 309-325.

Nguyen Van J., 1969. Structures, sensibilités et modalités d'action des caractères d'aggressivité. Ann. Amélior. Plantes, 4, 391-404.

Rotili P., 1975. Importanza degli effetti di associazione tra "genotipi " nel miglioramento genetico dell'erba medica. Riv. Agron., 2-3, 348-55.

Rotili P., 1979. Contribution à la mise au point d'une méthode de sélection de la luzerne prenant en compte les effets d'interférence entre les individus. I. Etude expérimentale de la structure de la luzernière. Ann. Amélior. Plantes, 29 (4), 353-381.
Rotili P., Zannone L., 1970. Intra and inter-genotypic competition in Medicago sativa L. Rep. of EUCARPIA Fodder Crops Sect. Meeting, Lusignan, 213-236.

Rotili P., Zannone L., 1971. The use of competition in the breeding of lucerne. Quadr. Sper. Ist. Forag. Lodi, 3, 41-86.

Rotili P., Zannone L., 1975. Principaux aspects d'une méthode de sélection de la luzerne basée sur des dispositifs qui utilisent la concurrence entre les plantes. Ann. Amélior. Plantes, 25 (1), 29-49.

Rotili P., Zannone L. 1977. Analisi degli effetti di associazione in popolazioni di Dactylis glomerata L. Ann. Ist. Sper. Colture Forag., Lodi, 4, 71-82.

Rotili P., Zannone L., Gnocchi G., 1977a. Effetti di associazione e densità in cloni di Festuca (Festuca arundinacea L.) Ann. Ist. Sper. Colture Forag., Lodi, 4, 83-96.

Rotili P., Zannone L., Jacquard P., 1976. Effects of association on the evaluation of lucerne populations. Ann. Amélior. Plantes, 26 (2), 139-155.

Rotili P., Zannone L., Jacquard P., 1977b. Analisi degli effetti di associazione in popolazioni di trifoglio violetto (Trifolium pratense L.) Ann. Ist. Sper. Colt. Forag., Lodi, 4, 57-69.

Spitters C. J. T., 1979. Competition and its consequences for selection in barley breeding. Agric. Res. Rep., 893, 268 pp.

Wit C. T. de, Van den Bergh J. P., 1965. Competition between her bage plants. Neth. J. Agric. Sci., 13, 212-221.

Zannone L., Assemat L., Rotili P., Jacquard P., 1983. An experimental study of intraspecific competition within several forage crops. Agronomie, 3 (5), 451-459. 